Journal of Computer Science 8 (6): 864-871, 2012

ISSN 1549-3636

(C) 2012 Science Publications

\title{
New Optical Splitter Design for Application in Fibre-to-the Home Passive Optical Network using Virtual Lab Platform
}

\author{
Mohd Syuhaimi Ab-Rahman, Ainon Najahah Abdul Aziz, \\ Aimi Amalin Khairuddin, Siti Asma Che Aziz and Kasmiran Jumari \\ Department of Electrical, Electronic and Systems Engineering, \\ Faculty of Engineering and Built Environment, Spectrum Technology Research Division, \\ Computer and Network Security Research Group, \\ Universiti Kebangsaan Malaysia 43600 UKM Bangi, Selangor, Malaysia
}

\begin{abstract}
Problem statement: In this study, authors present a new design of optical splitter to be applied in FTTH-PON named Multi Ratio Optical Splitter (MROS). MROS was introduced to enhance the power distribution in the optical network. Approach: We also bring in new approach for designing a new optical device that enable us to characterize and analyze the design from waveguide design layer to network layer before fabricated called virtual lab platform. Results: Waveguide design of MROS would be designed with device designing tool using Beam Propagation Method (BPM) as a wave propagator. MROS designed to divide the input power to different percentage on each arm therefore it could carry data to different users of various distances. This design then integrated into optical network for analysis of device performance. The analysis based on the losses of output power to the input, maximum Q factor, Bit Error Rate (BER) and achievable distance. The result shows that the total insertion loss for MROS before being exported was $0.4989 \mathrm{~dB}$ and $0.3835 \mathrm{~dB}$ after embedded into the network. The distance that the MROS could achieve was up to $50 \mathrm{~km}$ as compared to $1 \times 4$ Splitter that could only reach a maximum of $34 \mathrm{~km}$. As an upgrading from this study, the design of MROS could be modify with expanding the number of splitting arm which more customer from various distances could enjoy the service provided. Conclusion/Recommendations: The result obtained shows that the performance of design is correlated when embedded into the network and the virtual lab platform is suitable for characterizing new devices in the network prior to fabrication.
\end{abstract}

Key words: Multi Ratio Optical Splitter (MROS), Beam Propagation Method (BPM), Transverse Electric (TE), Transverse Magnetic (TM), Optical Line Terminal (OLT)

\section{INTRODUCTION}

Virtual lab design platform provides a method of how equipments that is usually prepared at laboratory is compensated with virtual equipment. Virtual lab platform that is developed in this study is a design laboratory that will be used in the photonics technology. New devices will be designed and embedded into the communication network virtually before they are sent for fabrication process. In order to test the stability and reliability of the laboratory, a new device known as the Multi Ratio Optical Splitter (MROS) is designed and characterized. The device is based on the design of common optical splitter except that it can reduce the power wastage. The input power is not equally distributed to each arm. Instead it distributes power according to the designer's desire.
The advantage of this design is that it can overcome the disparity in distance from one premise to another, particularly when the premise is outside the accepted radius. In this study, MROS had been designed by using device designing tool based on Beam Propagation Method (BPM) in order to get the desired output. It is based on the planar waveguide that have a high flexibility in terms of design and can be developed for a variety of usage. Research is done on optical splitter using symmetric Y-branch to get the equal splitting power from this device. Once the desired output is produced, the research has been resumed on the device by taking the value of the design parameters.

Beam Propagation Method (BPM) is a step by step method of investigating linear and nonlinear propagation of ligthwave through any waveguide

Corresponding Author: Mohd Syuhaimi Ab-Rahman, Department of Electrical, Electronic and Systems Engineering, Faculty of Engineering and Built Environment, Spectrum Technology Research Division, Computer and Network Security Research Group, Universiti Kebangsaan Malaysia 43600 UKM Bangi, Selangor, Malaysia 
medium. An optical field can be tracked at any point as it propagates along guiding structure in fibre optics Optiwave, 2010. The analysis of Beam Propagation Method that is based on the low-order finite difference algorithm is much easier to use (Yu et al., 1994). This method is used broadly for the application of optical waveguide because of its stability. The stability of this method is an advantage because it allows the design of a device without the need of consideration on the danger of diversion (Kawano and Kitoh, 2001) The BPM analysis is used to solve the scalar wave equations of polarizations Transverse Electric (TE) and Transverse Magnetic (TM). By using the beam propagation method employing the finite-difference method, the amplitude electric fields inside and outside of a slab structure can be analyzed. Beam propagation method, is a step by step technique for simulating the propagation of light in optical waveguides (Feit and Fleck, 1978; Song et al., 2003). BPM is a powerful tool for creating guided-wave optical devices using the mode combination approach like coupler, multiplexer and demultiplexer, splitter and optical combiners (Yusof, 2005). However, it has limitation towards the optical design which is based on the mirror or reflective concept such as distributed bragg reflector.

Waveguide is one of the important components in developing homogeneous optical device. Y-branch has a simple structure and yield high product fabricated with compact device with stable wide angle branching ratio and Planar Light wave Circuit (PLC) (Lin et al., 1999). Considering the ability of optical device to reduce losses such as absorption loss, scatter loss and radiation loss, suitable polymer which has low-loss criteria had been produced (Daum, 2002). One of the advantages of using polymer in producing optical integrated circuit is the cost of fabrication is low. In addition, polymer has the combination criteria of non linear electro-optic, photosensitive and thermo-optic (Kassim et al., 2004). Parameters such as refractive index, length and width of waveguide and also wide angle branching in Y-branch need to be analyzed by using simulation of BPM tool in order to get the optimum design. Research by simulation is important in getting the optimum value of design parameters for MROS device. Usually the results of the simulation will be the benchmark for the real output which will be compared with the MROS device once it been developed. Hence, this study will discussed about the simulation as the initial factor of development the real MROS device. In Fiber-To-The-Home (FTTH) application, optical splitter or Multi Ratio Optical Splitter (MROS) has been designed in order to reduce the wastage of power.

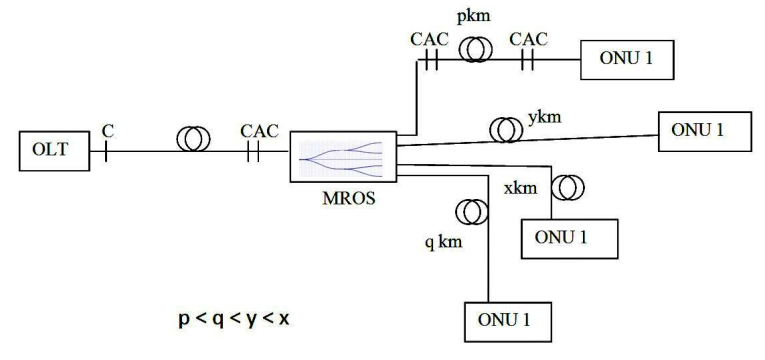

Fig. 1:Optical splitter in Fibre to the Home (FTTH) network

This optical device has also been developed to overcome the problem due to disparity in distance from one premise to another, particularly when the premise is exceeding the accepted radius. It can be overcome by customizing the power distribution based on the distance of every premise. With this, the signal can be extended to wider radius.

Application suggestion: Figure 1 presents the usage of optical moderator in the transmission network where its function is to divide the optical signal from Optical Line Terminal (OLT) to premises. For real network, the distance from each premise to OLT is not standardized; therefore MROS has been designed in order to cope with this situation. MROS that has four arms (branches) divides the power received into ratio 1:2:3:4. Number of arms of MROS and its power division ratio can be modified according to necessity. So the power losses during conveying the data can be reduced because the signal power is divided according to the distance of every house. Another advantage of MROS is this device does not use amplifier to divide the power signal to the different distance. MROS also can be used to divide the signals in various distances.

\section{MATERIALS AND METHODS}

Using device designing tool, OptiBPM, MROS was designed using optimum parameter value with four separated arms. The design was then simulated and characterized to get four different output power ratio for each arm. Based on results analyzed and supported by another value of parameters, the maximum cable distance for $1 \times 4$ Optical Splitter and MROS was calculated and compared. After that, the MROS design exported into optical network and simulation results were characterized. Exported MROS and 1x4 Optical Splitter was embedded into FTTH network design using OptiSystem. The maximum distance achieved by both splitter calculated based on output power, Qfactor and BER. 
Design of Multi Ratio Optical Splitter (MROS): MROS is designed based on the asymmetrical Y splitter where the output power of each arm is different. In this design, the input power is separated into four different percentages that is $10-40 \%$ on each arm. At the first phase, the power is divided in the ratio of $1: 1$, which means the input power is divided equally. For the second phase, the power for arm 3 and 4 is divided in the ratio of 1:4 where the first arm represents the $10 \%$ of the output power and the second arm represents $40 \%$ of the output power. For arm 5 and 6 , the power is divided in the ratio of $2: 3$ where the $20 \%$ of output power is at arm $5-30 \%$ at arm 6 . The width of the waveguide at second phase is set to be equal to the width of waveguide at first phase to avoid losses of power from the first phase. The angular divergence is manipulated to obtain the right portion of output. Parameter used in this waveguide design is shown in Table 1 and the layout of the design is shown in Fig. 2 and 3 shows the 3-D graph of effective index ratio of waveguide against propagation distance.

Simulation Characterization (BPM Tool): The design is first simulated using the BPM tool software to get the optimized performance of the device. Figure 4 shows the power distribution and their magnitude for each four output which are measured at the end of propagation. The total output power for this device is the sum of output on each arm:

\section{Total output power $=0.86736 \approx 86.7 \%$}

Total output power from all arm is expected to be equal to the input power. However, in practical there are various types of losses that affect the performance of the design. These losses are caused by scattering and absorption at the fiber cladding. According to the result from the Table 2, the total losses for MROS with an input power of 0.97295 calculated and can be seen in Table 3. The total loss for MROS is relatively small and acceptable with $10.85 \%$ of losses. The total insertion loss is still in the range of normal insertion loss of optical devices with insertion loss for overall MROS design is $0.4989 \mathrm{~dB}$. Arm 2 which has the least ratio of power division has the biggest value of insertion loss compare to the other arms with $10.18 \mathrm{~dB}$.

Calculating maximum cable distance: Maximum cable distance can be calculated if the number of connectors, splices and estimation of optical losses at each port of transmitter and receiver are known. The estimation of losses is $0.75 \mathrm{~dB}$ at each connector, $0.1 \mathrm{~dB}$ at each splice and addition of $3 \mathrm{~dB}$ as the margin of error (state the source of this estimation). The total loss at each unit for every component and the maximum distance that can be achieved is shown in Table 4.

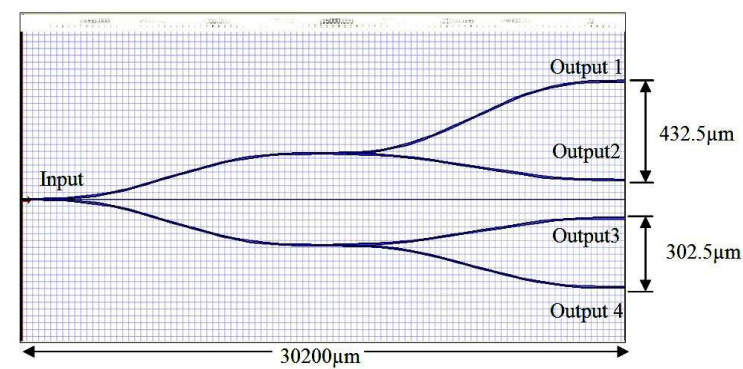

Fig. 2: Layout design of Multi Ratio Optical Splitter (MROS)

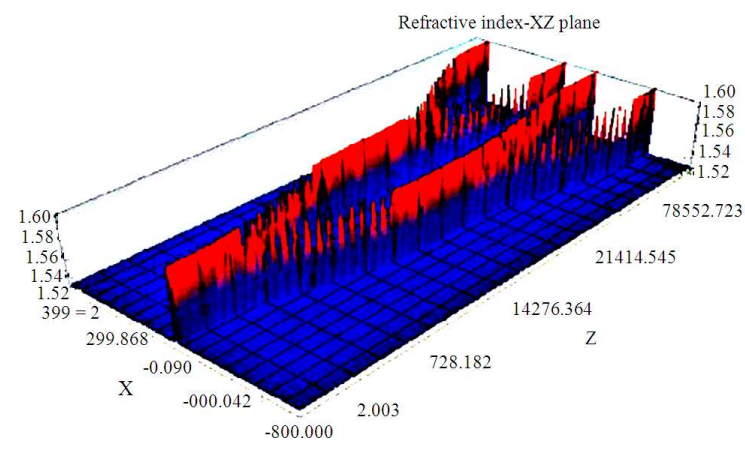

Fig. 3: 3-D graph of effective index ratio of waveguide against propagation distance

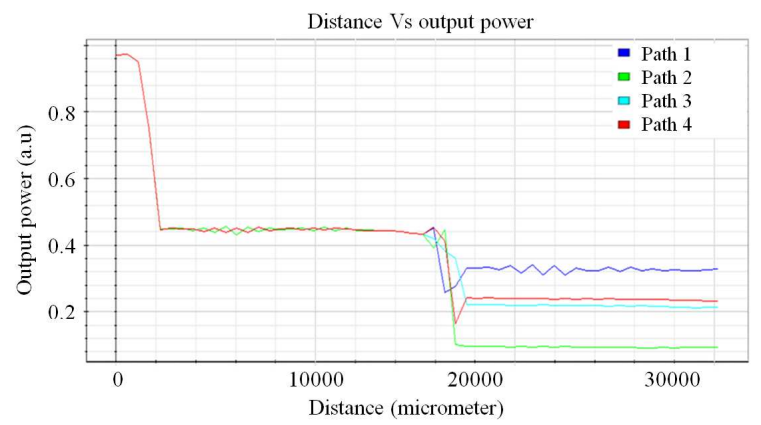

Fig. 4: Output power of each arm

Table 1: Data for each parameter

\begin{tabular}{ll}
\hline Parameter & Input data \\
\hline Substrate length & $32200 \mu \mathrm{m}$ \\
Substrate width & $1900 \mu \mathrm{m}$ \\
Refractive Index of substrate wafer, $\mathrm{n} 1$ & 1.522 \\
Refractive Index of & 1.599 \\
Waveguide substrate wafer, $\mathrm{n} 2$ & \\
Waveguide width & $6 \mu \mathrm{m}$ \\
Wavelength & $1.55 \mu \mathrm{m}$ \\
Medium & Gaussian \\
Polarization & TE, TM \\
Boundary condition & Simple TBC method \\
BPM solver & Paraxial \\
\hline
\end{tabular}


Table 2: Output power of each arm

\begin{tabular}{lllll}
\hline Arm & $\begin{array}{l}\text { Simulated } \\
\text { output power }\end{array}$ & $\begin{array}{l}\text { Percentage of } \\
\text { output power }(\%)\end{array}$ & $\begin{array}{l}\text { Actual } \\
\text { output power }\end{array}$ & \multicolumn{1}{l}{$\begin{array}{l}\text { Total } \\
\text { loss }\end{array}$} \\
\hline 1 & 0.32810 & 40 & 0.4 & 0.07190 \\
2 & 0.09343 & 10 & 0.1 & 0.00657 \\
3 & 0.21320 & 20 & 0.2 & -0.01320 \\
4 & 0.23263 & 30 & 0.3 & 0.06737 \\
\hline
\end{tabular}

Table 3: Value of total loss and insertion loss for each arm

\begin{tabular}{lll}
\hline Parameter & Formula & Value \\
\hline Total loss & $\frac{\mid \text { Pout }- \text { Pin } \mid}{\text { Pin }}$ & $0.10853 \approx 10.85 \%$ \\
Insertion loss & $10 \log _{10}$ Po/Pin & $0.4989 \mathrm{~dB}$ \\
Insertion loss arm 1, $\mathrm{L}_{1}$ & $10 \log _{10}$ Po2/Pin & $4.72 \mathrm{~dB}$ \\
Insertion loss arm 2, $\mathrm{L}_{2}$ & $10 \log _{10}$ Po2/Pin & $10.18 \mathrm{~dB}$ \\
Insertion loss arm 3, L & $10 \log _{10}$ Po3/Pin & $6.59 \mathrm{~dB}$ \\
Insertion loss arm 4, $\mathrm{L}_{4}$ & $10 \log _{10}$ Po4/Pin & $6.21 \mathrm{~dB}$ \\
\hline
\end{tabular}

Table 4: Values of insertion loss for every components

\begin{tabular}{lll}
\hline Item & Components & Insertion loss/unit \\
\hline 1 & Laser output & $0.0 \mathrm{~dB}$ \\
2 & Connector & $-0.75 \mathrm{~dB}$ \\
3 & Adaptor & $-0.20 \mathrm{~dB}$ \\
$4 \mathrm{a}$ & MROS insertion loss (Arm 1) & $-4.72 \mathrm{~dB}$ \\
$4 \mathrm{~b}$ & MROS insertion loss (Arm 2) & $-10.18 \mathrm{~dB}$ \\
$4 \mathrm{c}$ & MROS insertion loss (Arm 3) & $-6.59 \mathrm{~dB}$ \\
$4 \mathrm{~d}$ & MROS insertion loss (Arm 4) & $-6.21 \mathrm{~dB}$ \\
5 & Optical splitter insertion loss & $-7.3 \mathrm{~dB}$ \\
6 & Route loss & $-1.08 \mathrm{~dB}$ \\
7 & Fibre attenuation/km & $0.35 \mathrm{~dB} \mathrm{~km}$ \\
8 & Receiver (ONU) sensitivity & $-28.0 \mathrm{~dB}$ \\
\hline
\end{tabular}

The equation for maximum cable distance is:

[(PowerTP-SensitivityRP)-(LossC + LossA)-ILMROSIL] / Fiber Attenuation per km

Where:

PowerTP = Output power of transmitting port

SensitivityRP $=$ Minimum sensitivity of receiving port

LossC = Connector loss

Loss A $\quad=$ Adaptor loss

ILMROS = MROS insertion loss

IL $\quad=$ Insertion loss

The maximum cable distance for $1 \times 4$ Optical Splitter and MROS was calculated in Table 5 and 6.

\section{RESULTS AND DISCUSSION}

According to the calculation made in Table 5 for 1x4 Optical Splitter and Table 6 for MROS, the maximum distance that can be achieved by a normal $1 \times 4$ splitter is $39.34 \mathrm{~km}^{-1}$ for all arms. As for MROS, the maximum distance that can be achieved by each arm is different according to the percentage of output power. The distance that can be achieved by arm 1-4 is $46.71,31.11,41.37$ and $42.46 \mathrm{~km}^{-1}$ respectively. Based on the values obtained, MROS can carry data $7.37 \mathrm{~km}^{-1}$ farther than a normal $1 \times 4$ splitter

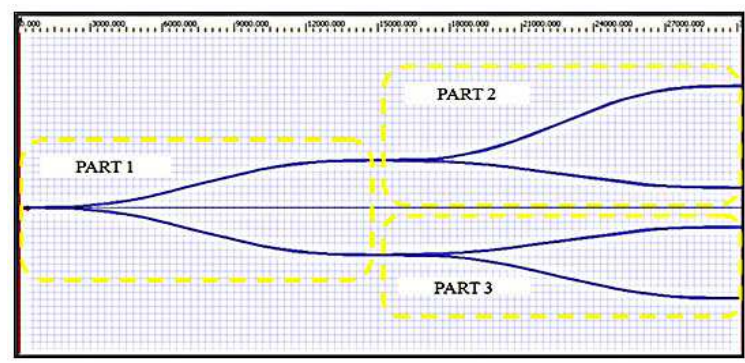

Fig. 5: Apportionment of MROS in BPM tool

Table 5: Maximum cable distance for normal $1 \times 4$ Optical Splitter

\begin{tabular}{lrrrr}
\hline Arm & 1 & \multicolumn{1}{c}{2} & \multicolumn{1}{c}{3} & \multicolumn{1}{c}{4} \\
\hline No. of connector (Unit) & 7.00 & 7.00 & 7.00 & 7.00 \\
Total connector loss (dB) & -5.25 & -5.25 & -5.25 & -5.25 \\
No. Of adaptor (Unit) & 3.00 & 3.00 & 3.00 & 3.00 \\
Total adaptor loss (dB) & -0.60 & -0.60 & -0.60 & -0.60 \\
MROS insertion loss (dB) & -7.30 & -7.30 & -7.30 & -7.30 \\
Route Loss (dB) & -1.08 & -1.08 & -1.08 & -1.08 \\
Fiber attenuation/km & 0.35 & 0.35 & 0.35 & 0.35 \\
Maximum cable distance $(\mathrm{km})$ & 39.34 & 39.34 & 39.34 & 39.34 \\
\hline
\end{tabular}

Table 6: Maximum cable distance for MROS

\begin{tabular}{lrrrr}
\hline Arm & \multicolumn{1}{l}{2} & \multicolumn{1}{c}{3} & \multicolumn{1}{c}{4} \\
\hline No. of connector (Unit) & 7.00 & 7.00 & 7.00 & 7.00 \\
Total connector loss (dB) & -5.25 & -5.25 & -5.25 & -5.25 \\
No. Of adaptor (Unit) & 3.00 & 3.00 & 3.00 & 3.00 \\
Total adaptor loss (dB) & -0.60 & -0.60 & -0.60 & -0.60 \\
MROS insertion loss (dB) & -4.72 & -10.18 & -6.59 & -6.21 \\
Route Loss (dB) & -1.08 & -1.08 & -1.08 & -1.08 \\
Fiber attenuation/km & 0.35 & 0.35 & 0.35 & 0.35 \\
Maximum cable distance (km) & 46.71 & 31.11 & 41.37 & 42.46 \\
\hline
\end{tabular}

Table 7: Output Power of each arm of MROS

\begin{tabular}{lllll}
\hline Arm & $\begin{array}{l}\text { Simulated } \\
\text { output power }\end{array}$ & $\begin{array}{l}\text { Percentage of } \\
\text { output power }(\%)\end{array}$ & $\begin{array}{l}\text { Actual } \\
\text { output power }\end{array}$ & $\begin{array}{l}\text { Total } \\
\text { loss }\end{array}$ \\
\hline 1 & 0.48007 & 50 & 0.5 & 0.01993 \\
2 & 0.48007 & 50 & 0.5 & 0.01993 \\
3 & 0.75278 & 80 & 0.8 & 0.04722 \\
4 & 0.19035 & 20 & 0.2 & 0.00965 \\
5 & 0.36677 & 40 & 0.4 & 0.03323 \\
6 & 0.55321 & 60 & 0.6 & 0.04679 \\
\hline
\end{tabular}

Exporting design into network design tool: Before exporting the design into the network design tool, MROS design in BPM tool need to be sliced into 3 parts as shown in Fig. 5 and has been simulated. Each part is simulated using BPM and the simulation result is shown in Table 7. The total output power at each part is the sum of output power of each arm in that part:

- $\quad$ Total output power of part $1=0.96014 \approx 96.0 \%$

- $\quad$ Total output power of part $2=0.94313 \approx 94.3 \%$

- $\quad$ Total output power of part $3=0.91998 \approx 92.0 \%$

Based on the total losses obtained, the total loss of each part with an input power of 0.97295 is can be seen in Table 8. 


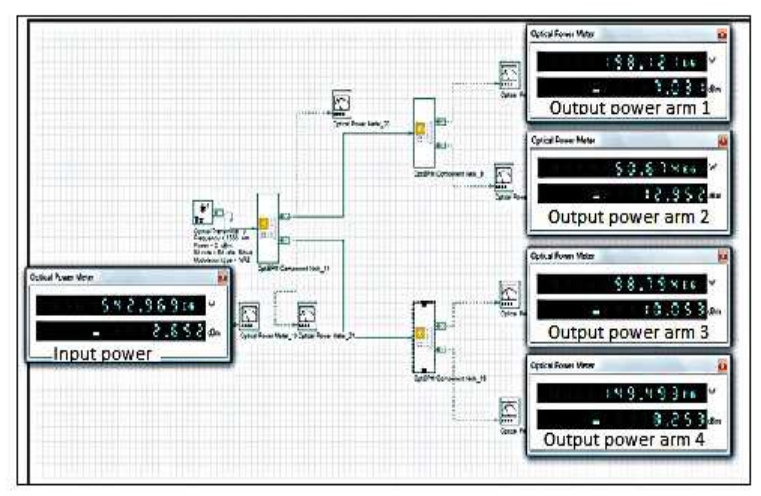

Fig. 6: Output power of each arm

Table 8: Value of total loss and insertion loss for each arm

\begin{tabular}{|c|c|c|}
\hline Parameter & Formula & Value \\
\hline \multirow{2}{*}{ Total losses of part 1} & Pout - Pin $\mid$ & \multirow{2}{*}{$0.01316 \approx 1.32 \%$} \\
\hline & Pin & \\
\hline \multirow{2}{*}{ Total losses of part 2} & Pout - Pin $\mid$ & \multirow{2}{*}{$0.03064 \approx 3.06 \%$} \\
\hline & Pin & \\
\hline \multirow[b]{2}{*}{ Total losses of part 3} & |Pout - Pin| & \multirow{2}{*}{$0.05297 \approx 5.30 \%$} \\
\hline & Pin & \\
\hline \multirow[b]{2}{*}{ Total Losses of MROS } & |Pout - Pin| & \multirow[b]{2}{*}{$0.09677 \approx 9.68 \%$} \\
\hline & Pin & \\
\hline Total insertion loss (Part 1), $\mathrm{L}_{1}$ & $10 \log _{10} \mathrm{Po} / \mathrm{Pin}$ & -0.0575 \\
\hline Total insertion loss (Part 2), $\mathrm{L}_{2}$ & $10 \log _{10} \mathrm{Po} / \mathrm{Pin}$ & $-0.1352 \mathrm{~dB}$ \\
\hline Total insertion loss (Part 3), $\mathrm{L}_{3}$ & $10 \log _{10} \mathrm{Po} / \mathrm{Pin}$ & $-0.2431 \mathrm{~dB}$ \\
\hline Total insertion loss of MROS, $\mathrm{L}$ & $10 \log _{10}$ Po/Pin & -0.4358 \\
\hline
\end{tabular}

Table 9: Output Power of MROS after simulated using network design tool software

\begin{tabular}{lclcl}
\hline & $\begin{array}{c}\text { Simulated output } \\
\text { Arm }\end{array}$ & $\begin{array}{l}\text { Percentage of } \\
\text { poutput power }\end{array}$ & $\begin{array}{l}\text { Actual output } \\
\text { power }(\mu \mathrm{W})\end{array}$ & $\begin{array}{l}\text { Total } \\
\text { loss }(\mu \mathrm{W})\end{array}$ \\
\hline 1 & 198.121 & 10 & 217.188 & 19.067 \\
2 & 50.674 & 40 & 54.297 & 3.623 \\
3 & 98.794 & 20 & 108.593 & 9.799 \\
4 & 149.493 & 30 & 162.891 & 13.398 \\
\hline
\end{tabular}

Table 10: Comparison of total insertion loss of MROS

\begin{tabular}{llll}
\hline Total insertion & $\begin{array}{l}\text { Overall design } \\
\text { (BPM tool) }\end{array}$ & $\begin{array}{l}\text { Part by part of the } \\
\text { design (BPM tool) }\end{array}$ \\
(Network design software)
\end{tabular}

The percentage of all types of losses is relatively low and still acceptable. Each part has a low insertion loss and still in the range of typical insertion loss of optical devices.

\section{Simulation Characterization (Network design tool):}

Each part that had been simulated in BPM tool is then exported into network design software and simulated separately to see the performance of the design before embedded into the network. The simulation result is shown in Fig. 6. Table 9 shows the output power of MROS after simulated in network design software.

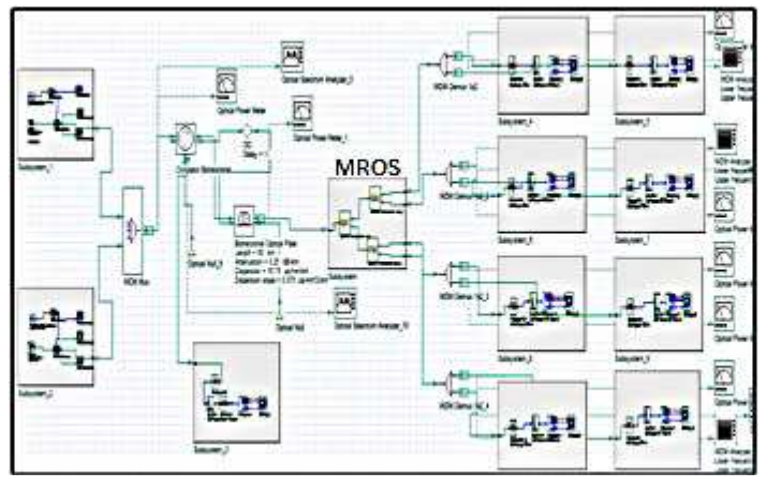

Fig. 7: FTTH (PON) Platform

By referring to Table 9, the total output power of MROS is the sum of output power on each arm.

Total Output Power $=497.082 \mu \mathrm{W}$

Based on the total loss on each arm, the total loss of MROS with an input power of $542.969 \mu \mathrm{W}$ is as follows:

Total Loss $=0.08451 \approx 8.45 \%$

Total Insertion Loss $=10 \log 10=-0.3835 \mathrm{~dB}$

The total loss is relatively small and acceptable. The total insertion loss is still in the range of normal insertion loss of optical devices. The comparison of total insertion loss when simulated using BPM tool and network design software, also with the output power when design is sliced into several parts is shown in Table 10. According to the result obtained as shown in Table 10, the insertion loss is decreasing as the design is sliced into several parts before exporting into network design software. The reduction is due to the fraction of power when the overall design is divided into parts. The division of the design reduced the loss due to fraction of light that propagates at the angular divergence. Instead the input signal splits equally before entering the second phase without passing through the angular divergence that has a very high possibility for loss to occur.

Embedding design into the FTTH PON network: The design that has already been simulated using the network design software is then embedded into the communication network to test the performance of the device as in Fig. 7. In this study, FTTH PON network platform that has a sensitivity of $-25 \mathrm{dBm}$ is chose as the test pad for the design. The simulated result of MROS is compared to the simulated result for $1 \times 4$ Optical Splitter. The comparison is made in terms of the maximum distance that can be achieved by both devices based on the output power, maximum $Q$ factor and BER on each arm. 

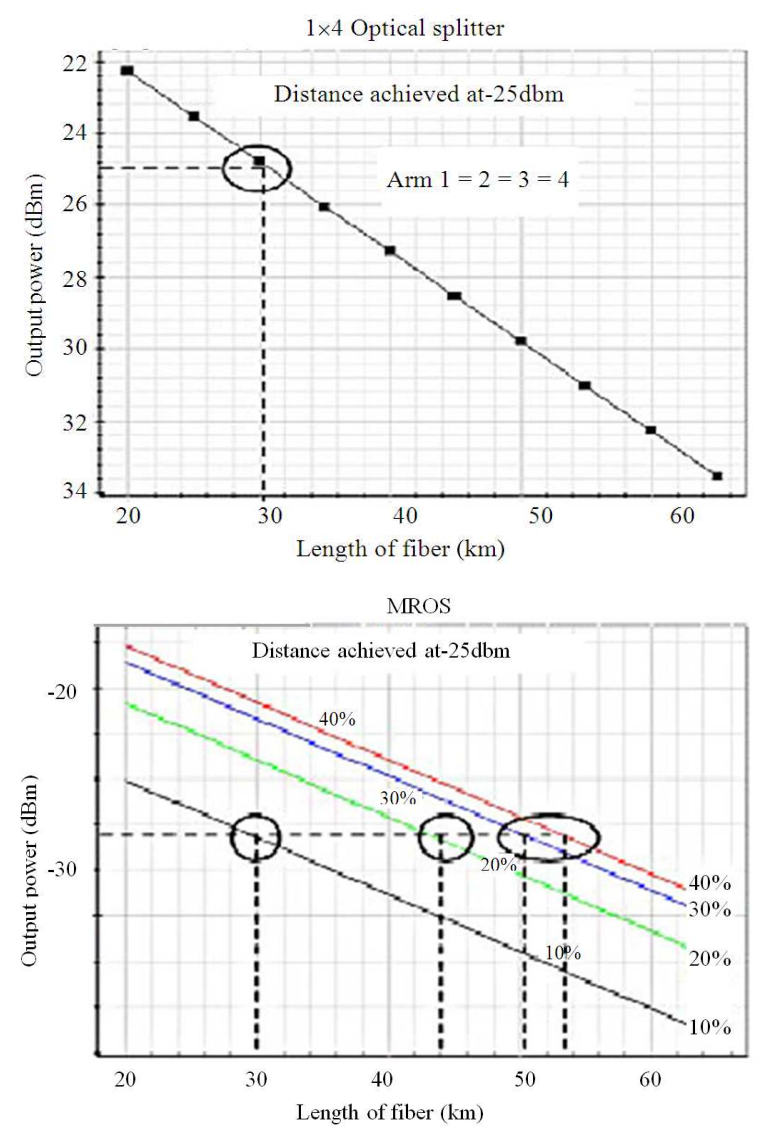

Fig. 8: Comparison of output power against distance of both splitters

Table 11: Comparison of distance based on output power

\begin{tabular}{lllll}
\hline & $\begin{array}{l}\text { Distance at } \\
\text { 10\% of Output } \\
\text { power } \pm \mathrm{km}\end{array}$ & $\begin{array}{l}\text { Distance at } \\
\begin{array}{l}20 \% \text { of output } \\
\text { power } \pm \mathrm{km}\end{array}\end{array}$ & $\begin{array}{l}\text { Distance at } \\
\text { 30\% of output } \\
\text { power } \pm \mathrm{km}\end{array}$ & $\begin{array}{l}\text { Distance at } \\
\text { 40\% of output } \\
\text { power } \pm \mathrm{km}\end{array}$ \\
\hline $\begin{array}{l}1 \times 4 \text { Optical splitter } \\
\text { Multi ratio } \\
\text { optical splitter }\end{array}$ & 24 & 31 & 31 & 31 \\
\hline
\end{tabular}

Table 12: Comparison of distance based on maximum $Q$ factor

\begin{tabular}{lllll}
\hline & $\begin{array}{l}\text { Distance at 10\% } \\
\text { of output } \\
\text { power } \pm \mathrm{km}\end{array}$ & $\begin{array}{l}\text { Distance at 20\% } \\
\text { of output } \\
\text { power } \pm \mathrm{km}\end{array}$ & $\begin{array}{l}\text { Distance at 30\% } \\
\text { of output } \\
\text { power } \pm \mathrm{km}\end{array}$ & $\begin{array}{l}\text { Distance at } \\
\text { of output } \\
\text { power } \pm \mathrm{km}\end{array}$ \\
\hline $\begin{array}{l}1 \times 4 \text { optical } \\
\text { splitter }\end{array}$ & 31 & 32 & 33 & 34 \\
$\begin{array}{l}\text { Multi ratio } \\
\text { optical splitter }\end{array}$ & 26.80 & 38.90 & 47.77 & 49.85 \\
\hline
\end{tabular}

Maximum distance based on the output power: Maximum distances that can be achieved by both splitters are measured when the output power is- 25 $\mathrm{dBm}$ because the platform used as the test pad is FTTH PON that has a sensitivity of $-25 \mathrm{dBm}$. The achievable distance extracted from both graphs of conventional $1 \times 4$ optical splitter and MROS in Fig. 8. The results were tabulated in Table 11, the maximum distance that can be achieved by all arms of $1 \times 4$ Optical Splitter is $\pm 31 \mathrm{~km}^{-1}$.
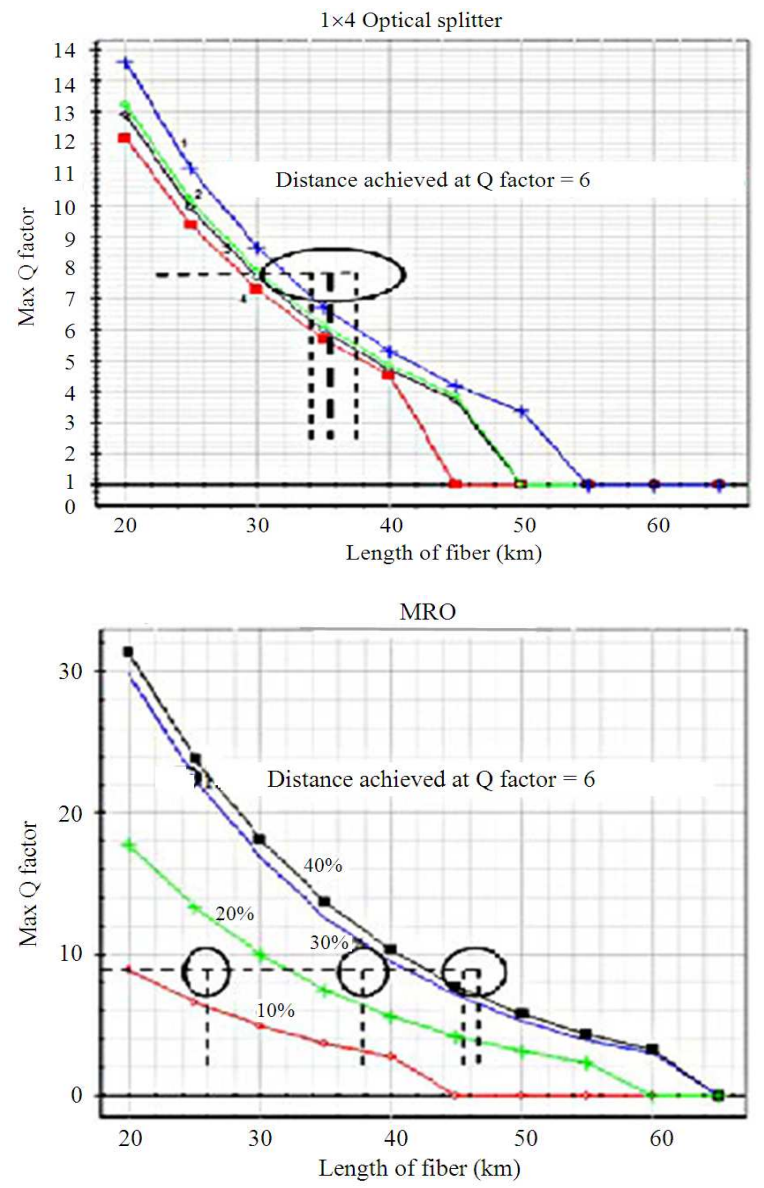

Fig. 9: Maximum Q factor against distance of both splitters

As for MROS, the distance that can be achieved is different according to the output power of each arm. At$25 \mathrm{dBm}$, the distance that can be achieved by arm 1 to arm 4 are $24, \pm 37, \pm 44$ and $\pm 47 \mathrm{~km}^{-1}$. From the result, it is proven that MROS can carry data $16 \mathrm{~km}^{-1}$ farther than a normal $1 \times 4$ Optical Splitter.

Maximum distance based on the maximum $Q$ factor: Maximum distance that can be achieved by both splitters is measured at the ideal value of maximum $Q$ factor; 6 as extracted from graph in Fig. 9 and presented in Table 12. A normal $1 \times 4$ Optical Splitter can achieve distances in the range of $30-34 \mathrm{~km}^{-1}$. As for MROS, the distances that can be achieved at each arm are 27, 39, 48 and $\pm 49 \mathrm{~km}^{-1}$. MROS is better for user whose located outside the accepted radius because it can carry data 16 $\mathrm{km}^{-1}$ farther than $1 \times 4$ optical splitter.

Maximum distance based on the Bit Error Rate (BER): Based on both graph shown in Fig. 10, distance that can be achieved by each arm is measured when BER value is at $1 \times 10-9$. 

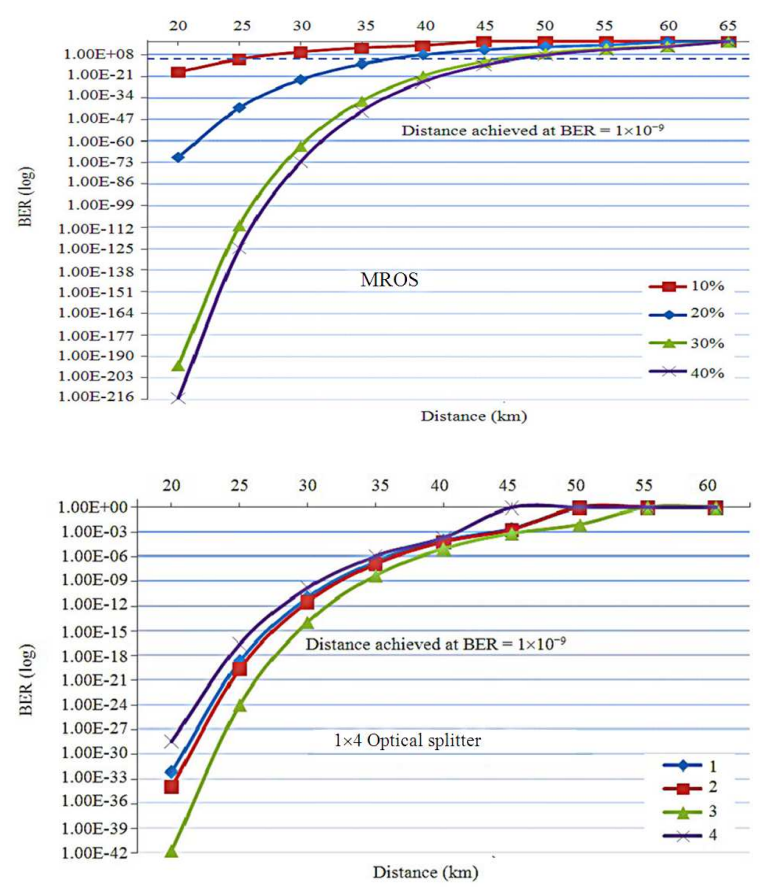

Fig. 10: Comparison of BER against distance for both splitter

This is the ideal value of BER on an eye diagram. The maximum distance that can be achieved by MROS is in the range of $25-50 \mathrm{~km}^{-1}$ as compared to normal $1 \times 4$ Splitter that can achieve the distance in the range of 31$34 \mathrm{~km}^{-1}$. From the graphs based on output power, maximum Q factor and BER, while MROS can carry data up to $50 \mathrm{~km}^{-1}$, the maximum distance that can be achieved by a normal $1 \times 4$ Splitter is only up to $34 \mathrm{~km}^{-1}$. From this comparison, it can be said that MROS is more efficient because it can carry data to different distances without wasting any power and the distance that can be achieved is much farther that a normal $1 \times 4$ optical splitter.

Analysis of device performance in the network: The maximum distance that can be achieved by each arm of $1 \times 4$ Optical Splitter is compared between calculation and simulation result. The calculation is made using the theoretical formula based on the result of output power obtained by simulation using BPM tool. The maximum distance that can be achieved using network design tool is based on the output power and maximum $\mathrm{Q}$ factor. By referring to the curve in the graphs in Fig. 11, it can be seen that the distance that can be achieved by each arm is almost equal. This is because of the same output at each arm. The calculation result shows that the data can be carried at a longer distance as compared to the simulation result. This is because of the total losses that is used in the calculation is an estimated value which is relatively lower than the actual losses.

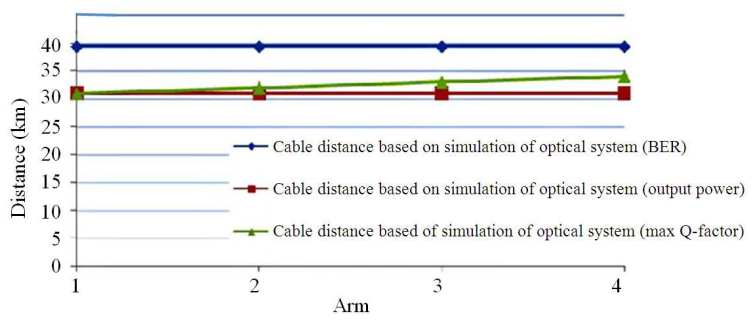

Fig. 11: Graph of distance against $1 \times 4$ optical Splitter's arms

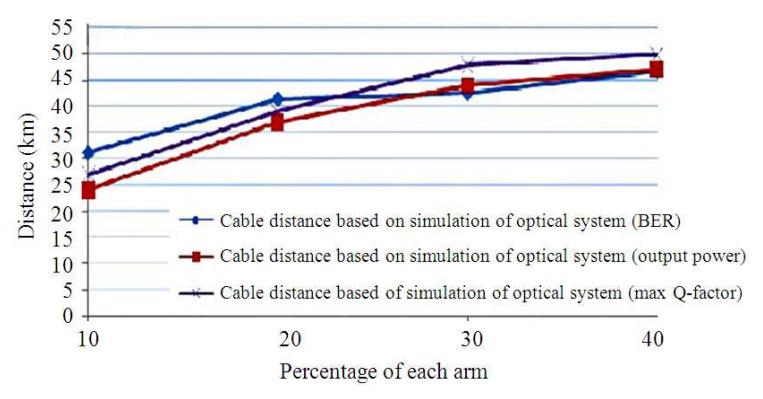

Fig. 12: Graph of distance against MROS' arms

When the loss is higher, the distance that can be achieved is nearer. The wastage of power happens when the location of the user is near to the OLT because the fraction of power that is distributed to each arm the equal.

The calculated and simulated distance for MROS is compared as shown in Fig. 12. Calculation is made based on the theoretical formula based on the output power obtained by simulation using BPM tool with estimated losses. The maximum distance achieved using simulation is based on the output power and the maximum $\mathrm{Q}$ factor. As seen in the graph, the distance achieved by each arm is different according to its percentage of output power. The curve based on the calculation is high at the first two arms and lower at the last two arms. This is because of the output power that is obtained in simulation using BPM tool is low and it affects the calculation as the theoretical formula uses the simulation result to calculate the distance that it can achieve. As for the distance based on the simulation by network design software, the distance that each arm can achieve is increasing according to the percentage of output power. The distance is farther as the percentage of output power is higher.

The wastage of power can be reduced because the maximum distance that can be achieved by each arm is different. The user in the location nearer to the OLT will get the data from the arm that has the lowest output power and the user at the farthest location will get data from arm that has the highest output power. 
Table 13: Comparison of MROS and a normal $1 \times 4$ splitter

\begin{tabular}{ll}
\hline Multi ratio optical splitter & $1 \times 4$ Splitter \\
\hline Designed to reduce power wastage & $\begin{array}{l}\text { Power wastage happens due to } \\
\text { different distance between nodes } \\
\text { Fixed output power }\end{array}$ \\
$\begin{array}{l}\text { Output power can be } \\
\text { customized as desired } \\
\begin{array}{l}\text { Design is based on the } \\
\text { commercial polymer SU-8 material }\end{array}\end{array}$ & $\begin{array}{l}\text { Design is based on variety } \\
\text { of material. } \\
\text { The SU-8 material used is for } \\
\text { Mavelength that is over } 1550 \mathrm{~nm}\end{array}$ \\
$\begin{array}{l}1310,1383 \text { and } 1460 \mathrm{~nm}, \\
1550 \text { and } 1625 \mathrm{~nm} .\end{array}$ \\
$\begin{array}{l}\text { Variable distance of } \\
\text { users and terminal }\end{array}$ & $\begin{array}{l}\text { Fixed distance between } \\
\text { users and terminal }\end{array}$ \\
\hline &
\end{tabular}

This device can be modified to get a desired output power and it is suitable for implementation in newly developed area where the location of the user and the terminal is varied. All the results from the simulation of MROS from both BPM and network design tools lead to the some features of MROS compared to $1 \times 4$ Optical Splitter. Several features of these two optical splitters has been identified and listed in Table 13 .

\section{CONCLUSION}

From the simulation and analysis that has been made, this virtual lab can be used to test the performance of the device before and after it is embedded into the network. Simulation characterization between BPM tool and network design tool has been carried and the difference of the characterization is not obviously different. The total loss in BPM tool and network design tool is relatively low and the device shows a better performance after being exported into network design software. However, the optimization result from network design software is strongly based on the initial design using the BPM tool. If the design shows a poor performance in BPM tool, it will also affect the performance in network design tool software.

\section{REFERENCES}

Daum, W., 2002. POF-Polymer Optical Fibers for Data Communication. 1st Edn., Springer-Verlag, Berlin, ISBN-10: 3540420096, pp: 433.

Feit, M.D. and J.A. Jr. Fleck, 1978. Light propagation in graded-index optical fibers. Applied Opt., 17: 3990-3998. DOI: 10.1364/AO.17.003990

Kassim, N.M., A.B. Mohammad, A.S.M. Supa'at, M.H. Ibrahim and S.Y. Gang, 2004. Polymer material for optical devices application. Proceedings of the RF and Microwave Conference, Oct. 5-6, IEEE Xplore Press, pp: 277-280. DOI: 10.1109/RFM.2004.1411125

Kawano, K. and T. Kitoh, 2001. Introduction to Optical Waveguide Analysis: Solving Maxwell's Equations and the Schrödinger Equation. 1st Edn., John Wiley and Sons, New York, ISBN-10: 0471406341 pp: 275.

Lin, H.B., J.Y. Su, W.S. Wang and R.S. Cheng, 1999. Novel optical single-mode asymmetric y-branches for variable power splitting. J. Quantum Elect., 35: 1092-1096. DOI: 10.1109/3.772181

Song, W.J., G.H. Song, B.H. Ahn and M. Kang, 2003. Scalar BPM analyses of TE and TM polarized fields in bent waveguides. IEEE Trans. Antennas Propagation, 51: 1185-1198. DOI: 10.1109/TAP.2003.812272

Yu, J., D. Yevick and D. Weidman, 1994. A comparison of beam propagation and coupledmode methods: Application to optical fiber couplers. J. Lightwave Technol., 12: 797-802. DOI: $10.1109 / 50.293971$

Yusof, A., 2005. Teknik Gandingan PrismaUntuk Pencirian Pandu Gelombang Planar. Tesis Sarjana, Fakulti Kejuruteraan, Universiti Kebangsaan Malaysia, Bangi. 